\title{
CXCR4 and CXCR3 are two distinct prognostic biomarkers in breast cancer: Database mining for CXCR family members
}

\author{
KAIBO GUO $^{1 *}$, GUAN FENG $^{1 *}$, QINGYING YAN ${ }^{1}$, LEITAO SUN $^{1}$, KAI ZHANG $^{1}$, \\ FENGFEI SHEN $^{1}$, MINHE SHEN ${ }^{2}$ and SHANMING RUAN ${ }^{2}$ \\ ${ }^{1}$ The First Clinical Medical College of Zhejiang Chinese Medical University, Hangzhou, Zhejiang 310053; \\ ${ }^{2}$ Department of Medical Oncology, The First Affiliated Hospital of Zhejiang Chinese Medical University, \\ Hangzhou, Zhejiang 310006, P.R. China
}

Received October 29, 2018; Accepted June 4, 2019

DOI: $10.3892 / \mathrm{mmr} .2019 .10784$

\begin{abstract}
CXC chemokine receptors (CXCRs) and chemokines are involved in tissue development and homeostasis, including in cancer development and progression. To date, seven CXCRs have been identified. However, the expression of CXCRs and their influence on the occurrence and development of breast cancer (BC) requires further investigation. In the present study, mRNA expression levels of the seven CXCRs were compared between normal tissues and several cancer types using the Oncomine database. Highly expressed CXCRs were selected and the expression levels of these CXCRs were examined in different subtypes of BC using the Gene Expression-Based Outcome for Breast Cancer database. Finally, the prognostic value of these CXCRs was examined using Kaplan-Meier plotter. It was found that, compared with normal controls, transcripts of CXCR4 and CXCR3 were significantly overexpressed in BC samples compared with other CXCRs. Survival analysis showed that high expression of CXCR4 promoted the recurrence of BC but had no impact on overall survival (OS), while a high level of CXCR3 transcript expression was significantly associated with increased survival in patients with $\mathrm{BC}$. With regards to different subtypes of BC, the present study revealed that high CXCR4 transcript expression was significantly associated with both longer relapse-free survival and OS only in basal-like BC. Furthermore, CXCR4 promoted chemosensitivity in patients with basal-like $\mathrm{BC}$ and induced resistance against endocrine therapy for patients with
\end{abstract}

Correspondence to: Dr Shanming Ruan, Department of Medical Oncology, The First Affiliated Hospital of Zhejiang Chinese Medical University, 54 Youdian Road, Hangzhou, Zhejiang 310006, P.R. China

E-mail: shanmingruan@zcmu.edu.cn

${ }^{*}$ Contributed equally

Key words: CXC chemokine receptor, database mining, breast cancer, survival, chemosensitivity, endocrine therapy luminal A BC. Thus, CXCR4 and CXCR3 are two distinct prognostic biomarkers and further studies are required.

\section{Introduction}

In 2018, breast cancer (BC) was expected to account for $30 \%$ of all new cancer diagnoses in women, and remains the principal cause of mortality from cancer in women worldwide (1). Recently, emphasis has been on the tumorigenesis of the immune system and immunotherapy for BC (2).

Chemokines, known as chemotactic cytokines, are a family of small molecular weight proteins $(6-14 \mathrm{kDa})$ of the immune system, which bind to $\mathrm{G}$ protein-coupled receptors and participate in tissue maintenance and development, and in pathological conditions. Chemokines can be divided into four types according to their structural differences: CC, CXC, $\mathrm{XC}$, and CX3C (3). Increasing evidence shows that CXCRs and their ligands affect some cancer-associated processes, including tumor cell activation, proliferation, invasion and migration $(4,5)$.

CXCR1-CXCR7 have been identified (6). CXCR1/2 share $\sim 76 \%$ sequence homology and bind to CXC ligand 8 (CXCL8) with similar affinities (7-9). CXCR1/2 and CXCL8 play important roles in the initiation and transfer of inflammatory mediators, as well as in the related tumor growth and metastasis (10). The CXCL9, -10, -11/CXCR3 axis contributes to tumor suppression by regulating immune cell development, differentiation and activation through paracrine signaling. However, the axis also promotes tumor progression and metastasis through autocrine signaling (11). CXCR4, which is widely expressed on the surface of epithelial and endothelial cells (12), is activated by CXCL12. This generates signals for a number of processes leading to tissue remodeling, including the homeostasis and development of normal tissues, hemopoiesis and angiogenesis. These roles make CXCR4 an important player in tumorigenesis (13). CXCR5 is specifically expressed in Burkitt lymphoma and lymphoid tissues, and is important for B cell migration through its binding to CXCL13 (14). It was reported that increased CXCR5 expression may result in increased survival and migration of MCF-7 BC cells that lack functional cellular tumor antigen p53 (TP53) (15). CXCR6-positive cells are cancer stem cells that can generate 
tumors through the process of self-renewal and their ability to differentiate into multiple cell types, which may also play a role in the mechanism of CXCR6 in tumor progression (16). CXCR7 is also expressed in different types of cancer and on tumor-associated vasculature. Emerging evidence also reveals its participation in metastasis and tumor progression (16).

Individual CXCRs have discrete roles in cancer development and progression. Nevertheless, the contributions of distinct CXCRs to BC tumorigenesis need to be explored. Thus, in the present study, large databases were mined for transcription expression information about CXCR family members in $\mathrm{BC}$ and normal tissues. Finally, the expression levels of CXCR family members were analyzed in diverse subtypes of $\mathrm{BC}$ and the prognostic value of CXCR family members in BC was assessed.

\section{Materials and methods}

Oncomine database analysis. The transcript expression levels of different CXCRs in a variety of cancers were analyzed using the publicly available cancer microarray database Oncomine (http://www.oncomine.org), which contains numerous datasets, including The Cancer Genome Atlas (TCGA) dataset. In the present study, the thresholds were set as follows: Data type, mRNA; gene rank, all; fold change, 2; P-value, 0.01 . The differences in expression between cancer specimens and normal control datasets for CXCR family members were compared.

Gene expression-based outcome for breast cancer (GOBO) database analysis. The transcript levels of specific CXCRs in $\mathrm{BC}$ subtypes were analyzed using the GOBO database (http://co.bmc.lu.se/gobo). The GOBO database contains gene expression data about 1,881 $\mathrm{BC}$ samples and $51 \mathrm{BC}$ cell lines from experiments conducted using Affymetrix microarrays (17).

Survival analysis using the Kaplan-Meier (KM) plotter. The KM plotter tool (http://kmplot.com/analysis/) can be used to evaluate the influence of the expression of 54,675 genes on survival in 10,461 cancer samples, including relapse-free survival (RFS) and overall survival (OS), to determine the prognostic values of CXCRs in 5,143 BC patients.

The effects of specific CXCRs on the prognosis of BC were studied, according to the following criteria: All patients with $\mathrm{BC}$; the four molecular subtypes of $\mathrm{BC}$, according to the 2013 St. Gallen criteria (18), were basal-like [estrogen receptor (ER) and progesterone receptor (PR) absent, human epidermal growth factor receptor-2 (HER2) negative], luminal A [ER and PR positive, HER2 negative, Ki-67 'low' $(<14 \%)$ ], luminal B [ER positive, HER2 negative and at least one of the following: Ki-67 'high' $(\geq 20 \%)$, PR 'negative or low' $(<20 \%)$ or ER positive, HER 2 over-expressed or amplified, any Ki-67, any PR], HER2 (HER2 over-expressed or amplified, ER and PR absent); other characteristic molecular markers; related optimal treatment for different $\mathrm{BC}$ molecular subtypes, for example, basal-like $\mathrm{BC}$ with chemotherapy, luminal $\mathrm{A} \mathrm{BC}$ with endocrine therapy and luminal B BC with both chemotherapy and endocrine therapy. The results are presented using KM curves, with the hazard ratio (HR) with $95 \%$ confidence intervals $(95 \% \mathrm{CI})$ and the P-value for the log-rank test displayed.

\section{Results}

CXCR4 and CXCR3 are significantly overexpressed in BC. To date, it has been determined that there are seven CXCR family members expressed in a variety of human cancer types (Fig. 1). Utilizing the Oncomine database for gene expression analysis in BC, 15 out of 50 analyses met the threshold for CXCR 4 in 9 out of 13 datasets, while 6 out of 43 analyses met the threshold for CXCR3 in 5 out of 10 datasets. No fold change $>2$ was found between $\mathrm{BC}$ samples and normal tissues for the transcript expression of CXCR1 (fold change $=1.074$; $\mathrm{P}=0.163$; Fig. 2A), $\mathrm{CXCR} 2$ (fold change $=-1.095 ; \mathrm{P}=0.795$; Fig. 2B), CXCR5 (fold change $=1.119 ; \mathrm{P}=1.87 \times 10^{-4}$; Fig. 2G), CXCR6 (fold change $=1.713 ; \mathrm{P}=7.19 \times 10-5 ;$ Fig. $2 \mathrm{H}$ ) and CXCR7 (fold change $=-2.448 ; \mathrm{P}=1.000 ;$ Fig. 2I).

The analysis showed that the CXCR3 transcript was significantly elevated in $\mathrm{BC}$ samples compared with normal tissues. The CXCR3 transcript level was 2.200 -fold $\left(\mathrm{P}=1.52 \times 10^{-9}\right)$ higher in $\mathrm{BC}$ samples in a large-sample dataset from TCGA database (Fig. 2C). Similarly, in a previous study by Curtis et al (19), CXCR3 was elevated by 2.857 -fold $\left(\mathrm{P}=4.20 \times 10^{-11}\right)$ in $\mathrm{BC}$ compared with normal samples (Fig. 2D).

The transcript level of CXCR4 was 2.079-fold $\left(\mathrm{P}=2.69 \times 10^{-10}\right)$ higher in $\mathrm{BC}$ compared with normal samples in a 593-sample dataset from TCGA database (Fig. 2E). Furthermore, in a 59 sample dataset from a previous study by Finak et al (20), CXCR4 mRNA expression was increased by 7.230 -fold $\left(\mathrm{P}=8.95 \times 10^{-19}\right)$ in $\mathrm{BC}$ tissues compared with normal samples (Fig. 2F).

In different breast cancer cell lines, the Neve (21) expression and intensity of CXCR3 3 and CXCR4 differ (Figs. 3E and 4E), which may provide a reference to the selection of cell lines for basic experiments.

Expression of CXCR4 and CXCR 3 in different molecular subtypes of $B C$. In the present study, CXCR4 and CXCR 3 were identified as being overexpressed in $\mathrm{BC}$. To further explore the expression of CXCR4 and CXCR3, their expression levels were analyzed in different molecular subtypes of BC. The dataset from a previous study by Farmer et al (22) revealed that CXCR4 was increased by 1.496 -fold $\left(\mathrm{P}=5.75 \times 10^{-4}\right)$ in basal-like BC samples compared to luminal-like $\mathrm{BC}$ samples (Fig. 3A), while CXCR3 showed no significant difference between these two subtypes of $\mathrm{BC}(\mathrm{P}=0.18$; Fig. $4 \mathrm{~A})$.

Basal-like subtype can be classified as basal A and basal B. In GOBO analysis, CXCR4 expression in luminal-like BC was statistically higher $(\mathrm{P}=0.01784)$ than in the basal $\mathrm{A}$ or basal $\mathrm{B}$ subtypes of $\mathrm{BC}$, and the basal-like subtype of $\mathrm{BC}$ expressed higher levels of CXCR4 $(\mathrm{P}<0.00001)$ than in the luminal A or luminal B subtype (Fig. 3B-D). The hormone receptor sensitive subtype of $\mathrm{BC}$ was not significantly different $(\mathrm{P}=0.12853)$ than the triple negative $\mathrm{BC}$ (TNBC) or HER2 subtypes in terms of CXCR4 expression (Fig. 3D). But, CXCR3 showed no significant difference in expression among the different molecular subtypes of BC (Fig. 4B-D).

CXCR4 expression predicts better survival in patients with ER-negative/TP53-mutated basal-like BC, in patients with basal-like $B C$ treated with chemotherapy and in patients with luminal $A B C$ not treated with endocrine therapy. The 


\begin{tabular}{|c|c|c|c|c|c|c|c|c|c|c|c|c|c|c|}
\hline \multirow{2}{*}{$\begin{array}{l}\text { Analysis Type by Cancer } \\
\text { Bladder Cancer }\end{array}$} & \multicolumn{2}{|c|}{ 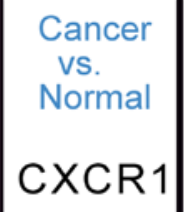 } & \multicolumn{2}{|c|}{$\begin{array}{c}\text { Cancer } \\
\text { vs. } \\
\text { Normal } \\
\text { CXCR2 }\end{array}$} & \multicolumn{2}{|c|}{$\begin{array}{c}\text { Cancer } \\
\text { vs. } \\
\text { Normal } \\
\text { CXCR3 }\end{array}$} & \multicolumn{2}{|c|}{$\begin{array}{l}\text { Cancer } \\
\text { vs. } \\
\text { Normal } \\
\text { CXCR4 }\end{array}$} & \multicolumn{2}{|c|}{$\begin{array}{c}\text { Cancer } \\
\text { vs. } \\
\text { Normal } \\
\text { CXCR5 }\end{array}$} & \multicolumn{2}{|c|}{$\begin{array}{l}\text { Cancer } \\
\text { vs. } \\
\text { Normal } \\
\text { CXCR6 }\end{array}$} & \multicolumn{2}{|c|}{$\begin{array}{l}\text { Cancer } \\
\text { vs. } \\
\text { Normal } \\
\text { CXCR7 }\end{array}$} \\
\hline & & & 1 & & & & 1 & 2 & & & & & & 2 \\
\hline Brain and CNS Cancer & & 1 & 1 & 2 & & 4 & 11 & & 1 & 1 & 2 & & 11 & \\
\hline Breast Cancer & & & & & 6 & & 15 & & 2 & & 2 & & 2 & 17 \\
\hline Cervical Cancer & & & & 4 & & 1 & 1 & & & & & & 3 & \\
\hline Colorectal Cancer & 1 & & 5 & & & 2 & & 1 & & 8 & & & 1 & 1 \\
\hline Esophageal Cancer & & & & 5 & & & 5 & & & & & & 2 & 1 \\
\hline Gastric Cancer & & & & . & & & 3 & & & 1 & & 1 & & 1 \\
\hline Head and Neck Cancer & & & & 9 & & & 4 & & 1 & 1 & 2 & & 6 & 2 \\
\hline Kidney Cancer & & 1 & & & & & 7 & & 1 & & 8 & 1 & 7 & 2 \\
\hline Leukemia & 1 & 4 & & 6 & & 1 & 1 & 1 & 3 & 6 & & 2 & 1 & 3 \\
\hline Liver Cancer & & & & 1 & & & 4 & & & & & & 3 & \\
\hline Lung Cancer & 1 & 5 & & 9 & & & 1 & 2 & 1 & 2 & & & 4 & 3 \\
\hline Lymphoma & & 1 & & & 3 & & 2 & 11 & & 12 & 13 & 4 & 6 & 2 \\
\hline Melanoma & & & & & & & 1 & 2 & 1 & & 1 & & & 3 \\
\hline Myeloma & & & & & 1 & & 1 & & & 1 & & & 1 & \\
\hline Other Cancer & & & 2 & 2 & 1 & 1 & 8 & & 1 & 1 & 1 & & 1 & 1 \\
\hline Ovarian Cancer & & 1 & & 1 & & & 2 & & & & & & & 1 \\
\hline Pancreatic Cancer & & & & 1 & & 1 & 6 & 1 & 1 & 2 & & & & \\
\hline Prostate Cancer & & & & & 1 & 1 & 1 & & & & & & & 2 \\
\hline Sarcoma & & & & 2 & 1 & & 2 & 1 & & 3 & & 2 & & 5 \\
\hline Significant Unique Analyses & 3 & 13 & 9 & 42 & 13 & 11 & 75 & 21 & 12 & 36 & 29 & 9 & 48 & 43 \\
\hline Total Unique Analyses & \multicolumn{2}{|c|}{301} & \multicolumn{2}{|c|}{304} & \multicolumn{2}{|c|}{295} & \multicolumn{2}{|c|}{336} & \multicolumn{2}{|c|}{338} & \multicolumn{2}{|c|}{336} & \multicolumn{2}{|c|}{345} \\
\hline
\end{tabular}

Figure 1. mRNA expression patterns of CXCR family members in different cancer types. Statistically significant differences in mRNA expression between tumors and normal tissues are shown; mRNA overexpression (red) and underexpression (blue) of the target gene. The number in each cell represents the number of analyses that met the threshold criteria (P-value, 0.01; fold change, 2; gene rank, all). Cell color is determined by the best gene rank percentile for the analyses within the cell. CXCR, CXC chemokine receptor; CNS, central nervous system.

prognostic value of CXCR4 in BC was evaluated and indicated that high expression of CXCR4 was significantly associated with a poorer RFS $(\mathrm{HR}=1.18 ; \mathrm{P}=0.0028)$ in all patients with BC (Fig. 5A). In Fig. 6A, a high CXCR4 transcript level was not significantly correlated with better $\mathrm{OS}(\mathrm{HR}=1.01 ; \mathrm{P}=0.9)$ in all patients with $\mathrm{BC}$.

Subtype analysis showed that a high level of CXCR4 transcript expression was positively correlated with a longer RFS in both TP53-mutated $(\mathrm{HR}=0.5 ; \mathrm{P}=0.0048)$ and basal-like $\mathrm{BC}(\mathrm{HR}=0.77 ; \mathrm{P}=0.043)$, while no statistical significance was found in TP53 wild-type or other molecular subtypes of BC (Fig. 5B-F and G). Similarly, the analysis also revealed that high transcript levels of CXCR4 were statistically correlated with better $\mathrm{OS}$ in patients with basal-like $\mathrm{BC}(\mathrm{HR}=0.52$; $\mathrm{P}=0.01)$ and in ER-negative $\mathrm{BC}(\mathrm{HR}=0.65 ; \mathrm{P}=0.034$; Fig. 6B-F and G).

High CXCR4 mRNA expression was statistically associated with a better RFS (HR=0.42; $\mathrm{P}=0.00095)$ and $\mathrm{OS}$ $(\mathrm{HR}=0.4 ; \mathrm{P}=0.035)$ in patients with basal-like $\mathrm{BC}$ treated with chemotherapy (Figs. 5H and I, and 6H and I). However, high expression of CXCR4 was significantly correlated with a poorer RFS (HR=1.44; $\mathrm{P}=0.045)$ in patients with luminal A BC treated with endocrine therapy (Fig. 5J and K).

High CXCR3 mRNA expression is correlated with a longer survival in patients with TP53-mutated/basal-like BC. High 
A

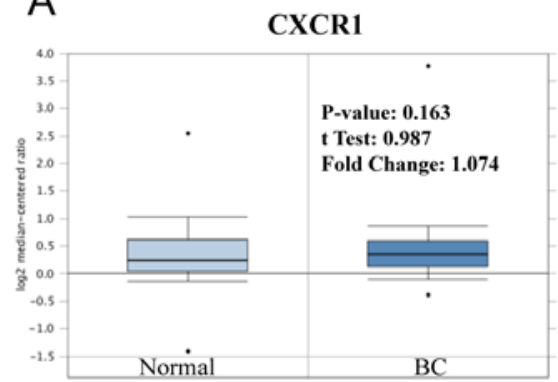

D

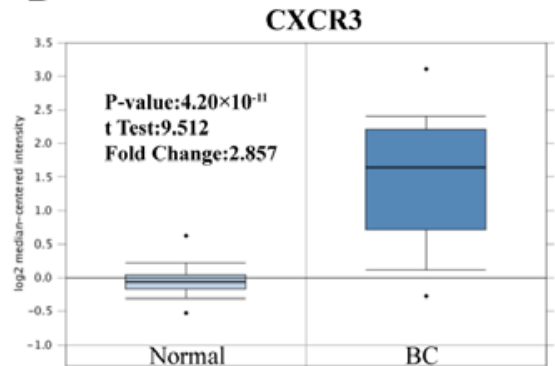

G

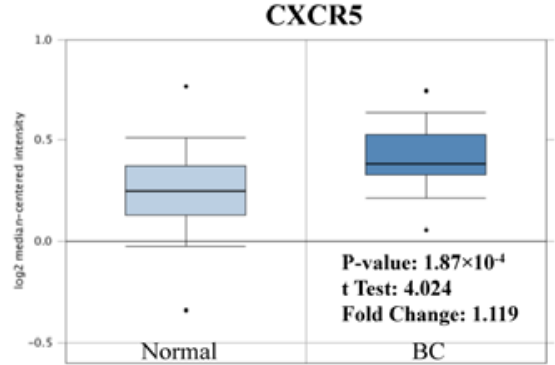

B

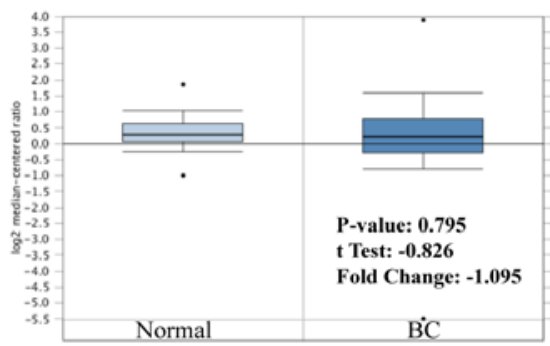

E

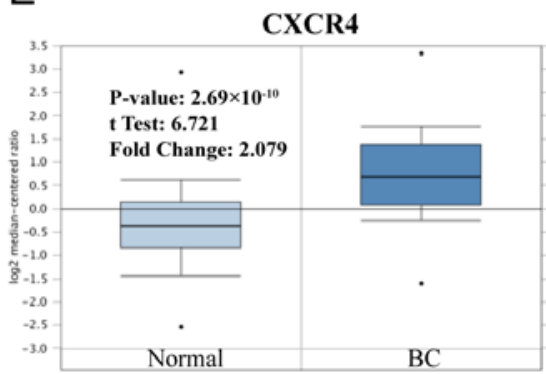

H

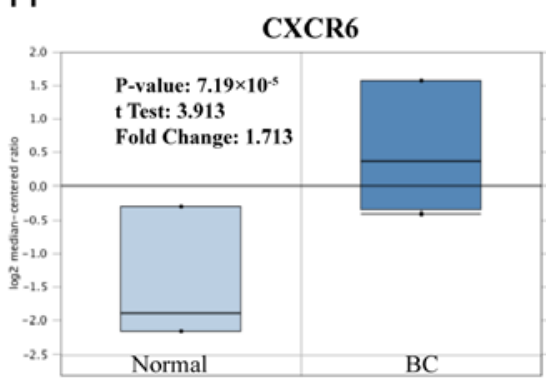

C

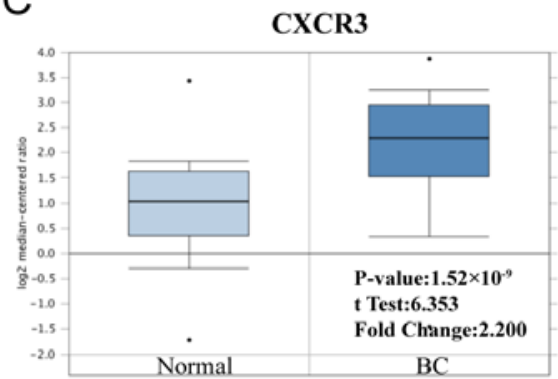

F

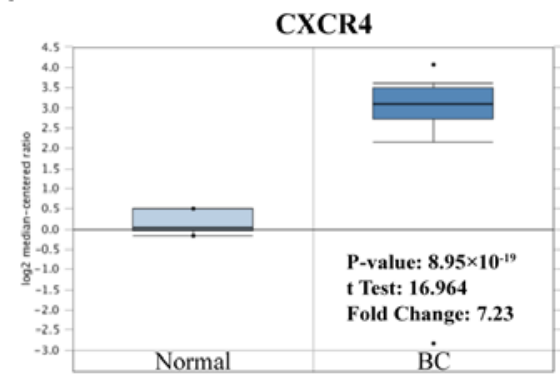

I

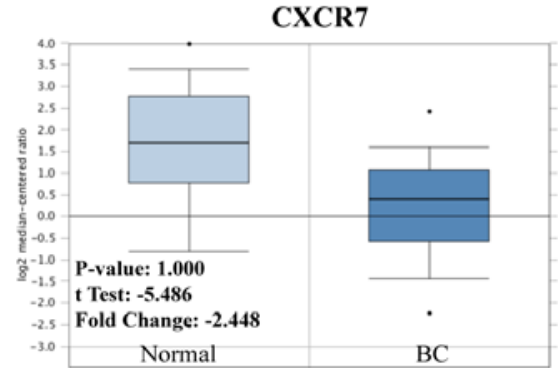

Figure 2. Analysis of CXCR family members in BC. Box plots were derived by comparing the expression of a specific CXCR family member in normal and $\mathrm{BC}$ tissues from gene expression data in the Oncomine database. $\mathrm{P}>0.01$ and fold change $>2$ demonstrate statistical significance. Comparison of (A) $\mathrm{CXCR} 1$ and (B) CXCR2 mRNA expression. Comparison of CXCR3 mRNA expression from a (C) TCGA dataset and (D) from a previous study by Curtis et al (19). Comparison of CXCR4 mRNA expression from a (E) TCGA dataset and (F) from a previous study by Finak et al (20). Comparison of CXCR4, (G) CXCR5, (H) CXCR6 and (I) CXCR7 mRNA expression levels. CXCR, CXC chemokine receptor; BC, breast cancer; TCGA, The Cancer Genome Atlas.

CXCR3 mRNA expression was statistically correlated with a better RFS $\left(\mathrm{HR}=0.74 ; \mathrm{P}=9.7 \times 10^{-8}\right)$ and $\mathrm{OS}(\mathrm{HR}=0.71$; $\mathrm{P}=0.0015$ ) in all patients with $\mathrm{BC}$ (Figs. 7A and 8A). Subtype analysis also showed that high CXCR3 mRNA expression was significantly associated with a longer $\mathrm{RFS}(\mathrm{HR}=0.55$; $\left.\mathrm{P}=2.6 \times 10^{-6}\right)$ and $\mathrm{OS}(\mathrm{HR}=0.51 ; \mathrm{P}=0.0073)$ in basal-like $\mathrm{BC}$ (Figs. 7B and 8B). Consistently, patients with mutated TP53 and with high levels of CXCR3 transcript expression were found to have longer RFS $(\mathrm{HR}=0.46 ; \mathrm{P}=0.0014)$ and $\mathrm{OS}(\mathrm{HR}=0.43$; $\mathrm{P}=0.032$ ) (Figs. 7G and $\mathrm{I}$, and $8 \mathrm{~J}$ and $\mathrm{K}$ ). However, high levels of CXCR3 transcript had a different effect on RFS and OS for some characteristic markers. The analysis predicted a better RFS in patients with luminal $\mathrm{A} \mathrm{BC}(\mathrm{HR}=0.8 ; \mathrm{P}=0.01)$ and luminal $\mathrm{B}$ BC $(\mathrm{HR}=0.7 ; \mathrm{P}=0.00024$; Fig. $7 \mathrm{C}-\mathrm{F}$ and $\mathrm{I})$, as well as a longer $\mathrm{OS}$ in patients with ER-negative $\mathrm{BC}(\mathrm{HR}=0.59$; $\mathrm{P}=0.0078)$ and lymph node positive $\mathrm{BC}(\mathrm{HR}=0.66 ; \mathrm{P}=0.04$; Fig. 8C-I).

\section{Discussion}

In the present study, the expression of CXCR family members was examined in different tumors, and it was indicated that CXCR4 and CXCR3 were highly expressed in BC. Subsequent analyses were performed to determine whether a correlation was present between the expression of CXCR4 and CXCR3 in the different molecular subtypes of $\mathrm{BC}$, and the survival rates associated with their expression. The results indicated that the mRNA expression of CXCR4 was statistically higher in patients with basal-like BC than in other subtypes, which is consistent with a previous report (23), and may explain why basal-like BC has a poorer prognosis than other subtypes. Survival analysis showed that high CXCR4 mRNA expression in BC promoted the recurrence of $\mathrm{BC}$, but did not have an impact on OS. There are many confounding factors influencing OS, including non-cancer-related mortality and participation in clinical trials. Two previous meta-analyses $(24,25)$ demonstrated that low CXCR4 mRNA expression in patients with BC is associated with better survival, including progression-free survival, disease-free survival and OS. In the present study, it was found that the impact of low CXCR4 mRNA expression on RFS is consistent with these previous studies $(24,25)$, while the results showed no difference in OS. The heterogeneity in OS between the combined meta-analysis 
A

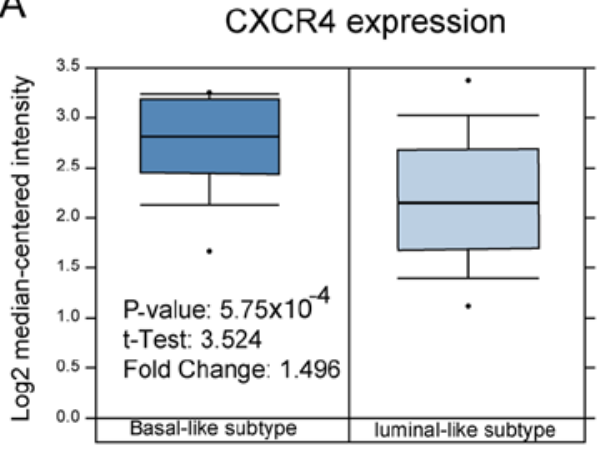

B

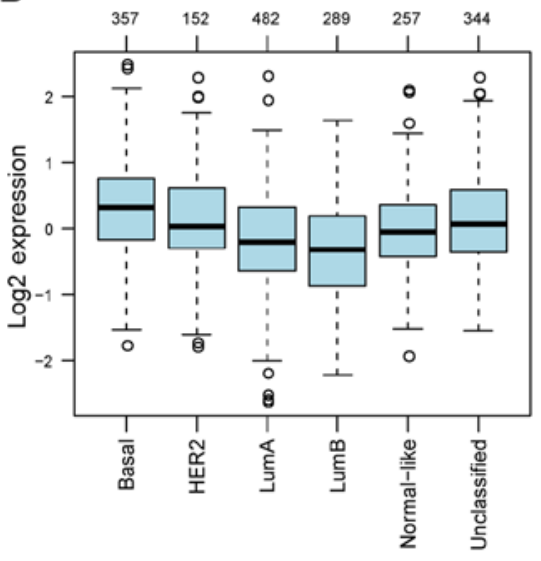

C

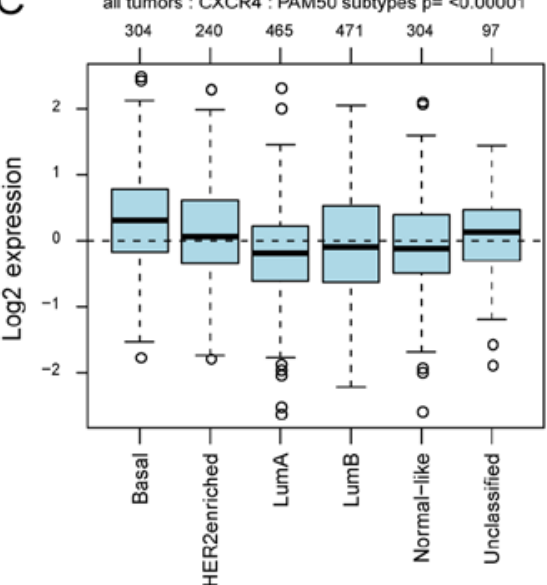

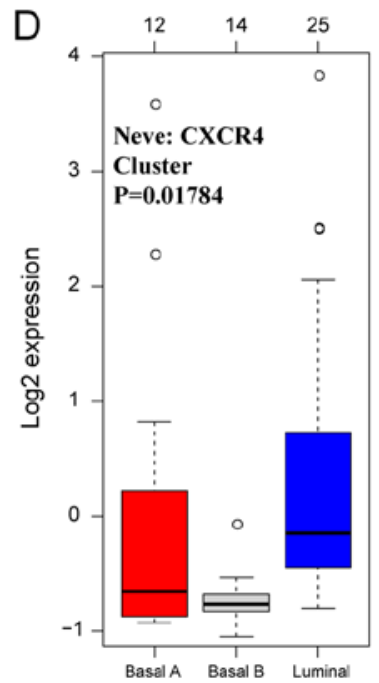
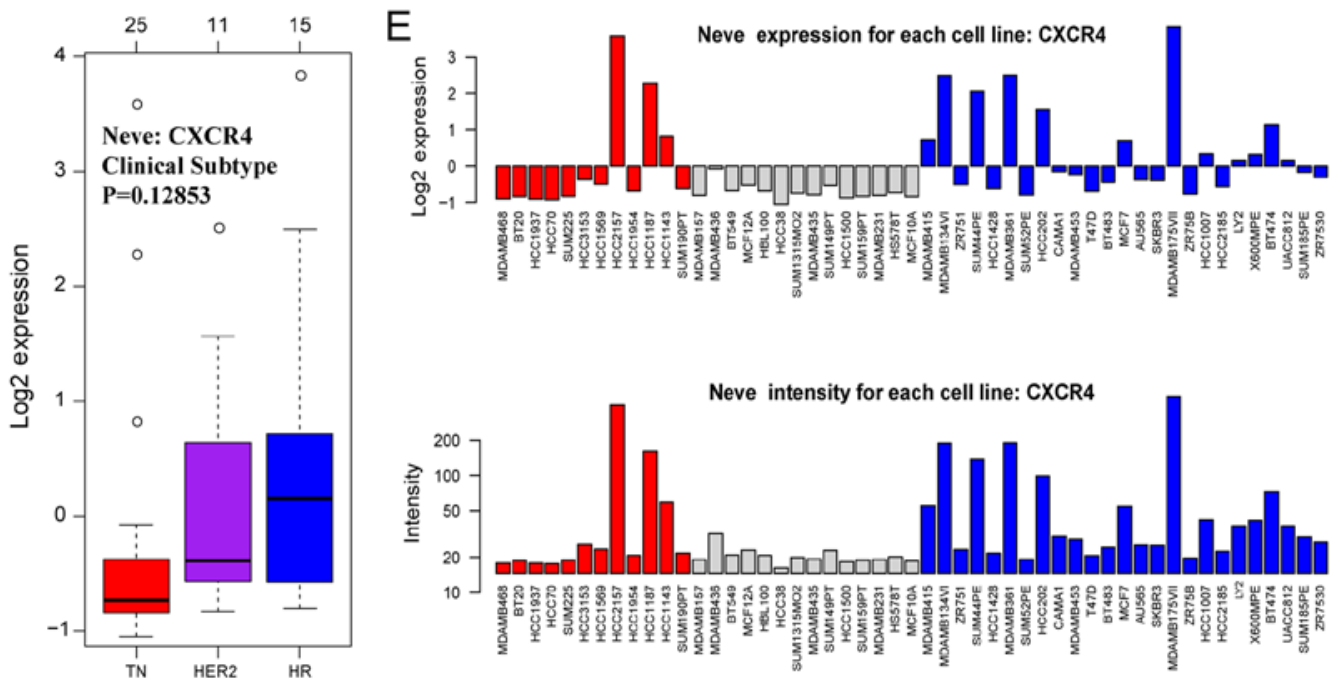

Figure 3. Correlation analysis of CXCR4 expression in different molecular subtypes of BC. (A) In the Oncomine analysis, the expression of CXCR4 in basal-like BC was significantly higher than that in luminal-like BC. In the GOBO analysis, the basal-like subtypes of BC expressed higher levels of CXCR4 than the luminal A, luminal B and HER2 subtypes of BC based on (B) HU and (C) PAM50 gene classifiers of BC. (D) The GOBO analysis also revealed that the expression of CXCR4 in luminal-like BC was significantly higher than that in the basal A or basal B subtypes of BC. (E) The Neve expression (21) of CXCR4 in BC cell lines. CXCR, CXC chemokine receptor; BC, breast cancer; lum, luminal; HER2, human epidermal growth factor receptor 2; HR, hormone receptor; TN, triple negative; GOBO, Gene Expression-Based Outcome for Breast Cancer.

studies is high $\left(\mathrm{I}^{2}=70 \%\right.$ and $\mathrm{P}<0.00001 ; \mathrm{I}^{2}=84.2 \%$ and $\mathrm{P}<0.001)(24,25)$. There is a discrepancy in the OS rates among the present study and previous studies $(24,25)$. Therefore, larger sample-sizes and high-quality trials are needed to show significance. In the present study, CXCR4 was found to be involved in $\mathrm{BC}$ tumorigenesis and to act as a prognostic biomarker for $\mathrm{BC}$, based on its high expression and correlation with survival.

A stratified analysis revealed that high CXCR4 levels in basal-like BC predicted a good clinical outcome, both in terms of RFS and OS. Basal-like BC accounts for $>70 \%$ of TNBC cases. Previous studies using small-sample sizes found the opposite result and support a negative role of CXCR4 in TNBC $(26,27)$ CXCR4 is thought to play an important role in promoting the proliferation, recurrence and metastasis of $\mathrm{BC}$, and may contribute to an adverse prognosis (28). However, a recent study reported that CXCR4 inhibitors were not efficient at inhibiting the growth of TNBC and even promoted the metastatic spread in $25 \%$ of cases (29). Therefore, this previous study indirectly supports the hypothesis that high CXCR4 expression predicts a favorable prognosis in TNBC. High
CXCR4 mRNA expression does not always promote migration. For example, Ierano et al (30) found that histone deacetylase inhibitors induced CXCR4 mRNA expression but antagonized CXCR4-mediated migration by inhibiting CXCR4 protein. In addition, the present study revealed that, as in patients with basal-like BC, high expression of CXCR4 predicted a better RFS and OS in patients with ER-negative and TP53-mutated $\mathrm{BC}$, respectively. This may be because an ER-negative status and TP53 mutation are features of TNBC (31). However, not all basal-like BC is TNBC (32), and as such, there may be discrepancies in the comparison between previous studies and the present study. Thus, more studies are required to clarify the relationship between CXCR4 expression and basal-like $\mathrm{BC}$ (or TNBC), and to understand the underlying molecular mechanism.

Next, the relationship between CXCR4 expression in different subtypes of $\mathrm{BC}$ was examined. Patients with basal-like $\mathrm{BC}$ are predominantly treated with chemotherapy. The results of the present study indicated that patients with basal-like BC and with high CXCR4 expression after chemotherapy have a more favorable prognosis, indicating 
A

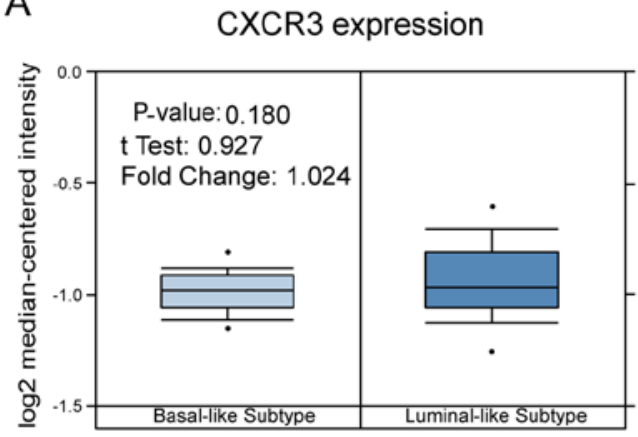

B

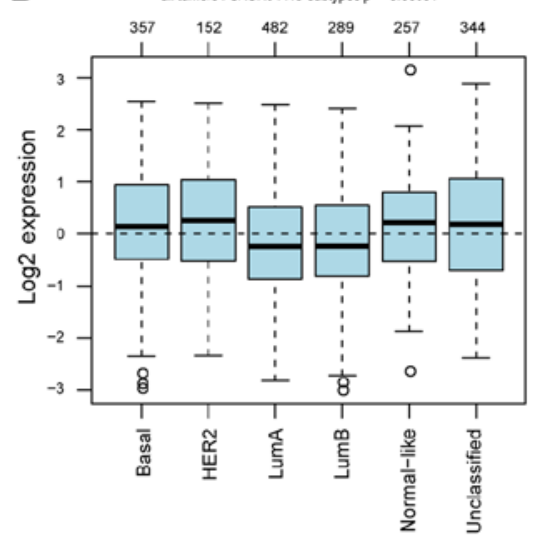

C
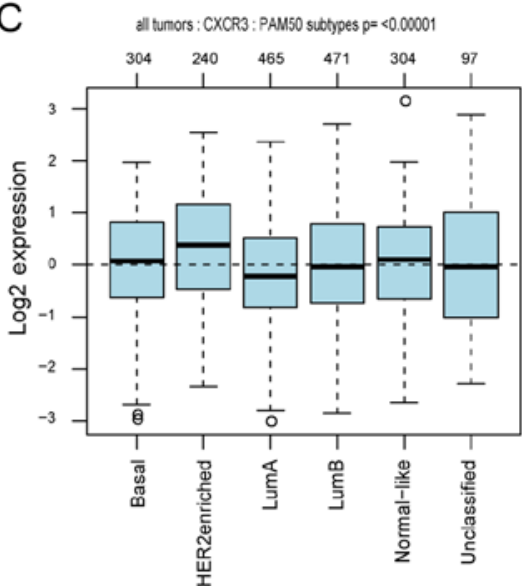
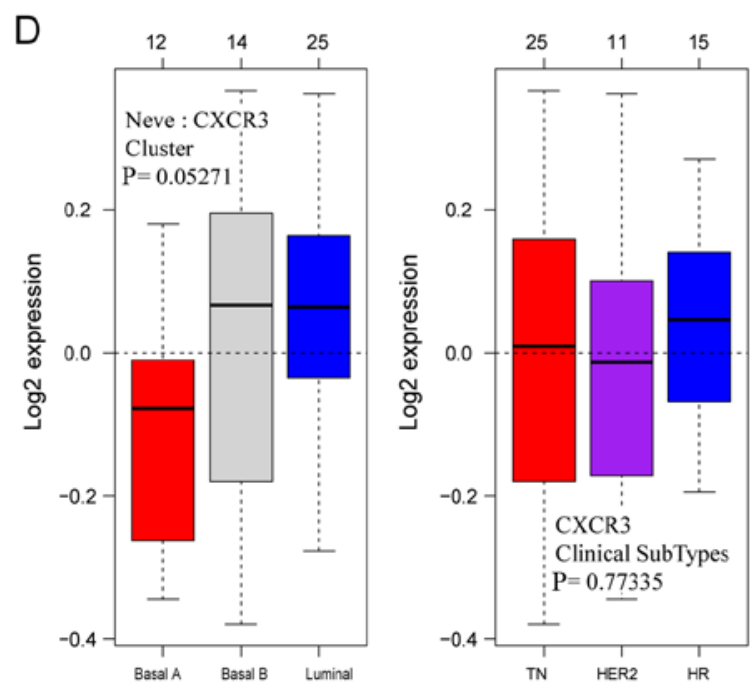

E

Neve expression for each cell line: CXCR3
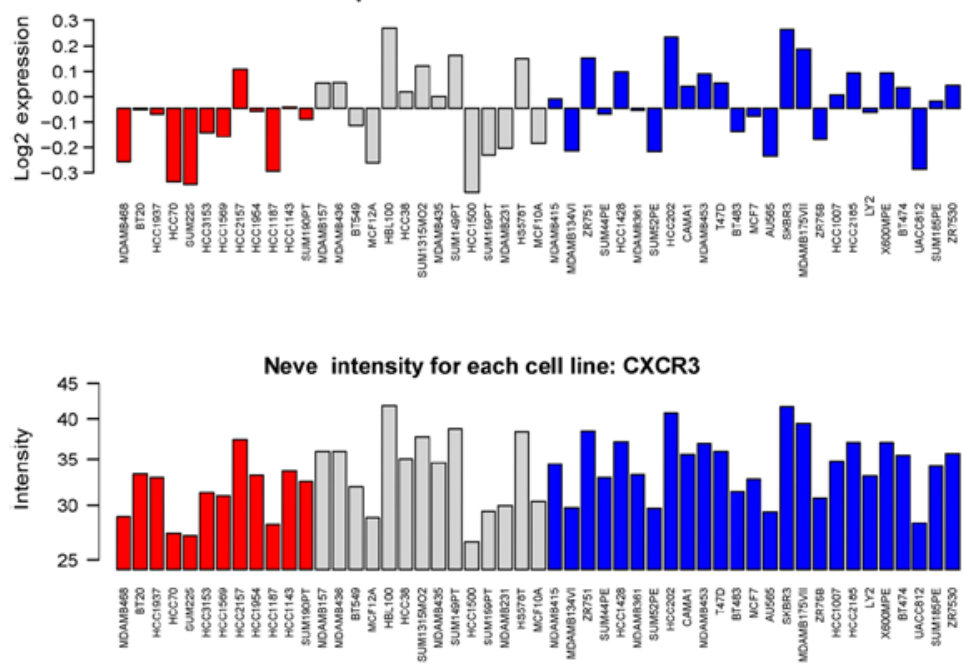

Figure 4. Correlation analysis of CXCR3 expression in different molecular subtypes of BC. (A) In the Oncomine analysis, CXCR3 expression showed no significant difference between the basal-like and luminal-like subtypes of $\mathrm{BC}$. In the GOBO analysis, there was no significant difference between the basal-like and luminal-like subtypes of BC based on the (B) HU and (C) PAM50 gene classifiers of BC. (D) The GOBO analysis also revealed that the expression of CXCR3 was not significantly different in the TN, HER2 and HR subtypes of BC. (E) The Neve expression (21) of CXCR4 in BC cell lines. CXCR, CXC chemokine receptor; $\mathrm{BC}$, breast cancer; lum, luminal; HER2, human epidermal growth factor receptor 2; HR, hormone receptor; TN, triple negative; GOBO, Gene Expression-Based Outcome for Breast Cancer.

that high expression of CXCR4 may increase the sensitivity of chemotherapy in basal-like BC. At present, few studies have reported on the relationship between the expression level of CXCR4 and the efficacy of chemotherapy, and these studies have used animal models or cell lines. For example, researchers found that CXCR4 induces chemoresistance in acute myeloid leukemia cells (OCI-AML3) and in colon cancer cells (HT-29 and SW480) $(33,34)$. Furthermore, Liang et al (35) reported that the silencing of CXCR4 sensitized TNBC cells to cisplatin. However, chemotherapy for basal-like BC typically consists of paclitaxel and anthracyclines. Another previous study showed that patients with BC have decreased expression of CXCR4 and HER 2 after neoadjuvant chemotherapy, indicating that these two genes may be a part of the mechanism of chemotherapy in BC (36). These previous studies may not support the results of the present study; therefore, more clinical trials are required to elucidate the role of CXCR4 in the efficacy of different chemotherapy regimens in basal-like BC. Furthermore, more experiments are required to understand the underlying molecular mechanism. To the best of our knowledge, the present study was the first to show that patients with luminal A BC and with high levels of CXCR4 expression after endocrine therapy have a shorter RFS than those with a low level of CXCR4 expression. Therefore, the present study indicated that CXCR4 may be a cause of resistance to endocrine therapy. Rhodes et al (37) found that the effects of CXCR4 overexpression were correlated with stromal cell-derived factor-1-mediated activation of downstream signaling through ERK1/2 and p38 MAPK. CXCR4 overexpression was also associated with increased ER-mediated gene expression, indicating that increased CXCR4 signaling is sufficient to drive ER-positive breast cancer to a metastatic and endocrine therapy-resistant phenotype through enhanced MAPK signaling. As patients with luminal A BC are usually only treated with adjuvant endocrine therapy (38), the efficacy of treatment can be predicted using CXCR4 expression.

The number of studies about CXCR3 in BC is fewer than that for CXCR4. CXCR3 has three isoforms, CXCR3-A, CXCR3-B and CXCR3-alt. CXCR3-A and CXCR3-B are the predominant isoforms and have different roles in $\mathrm{BC}$; signaling through CXCR3-A promotes tumor growth while CXCR3-B 

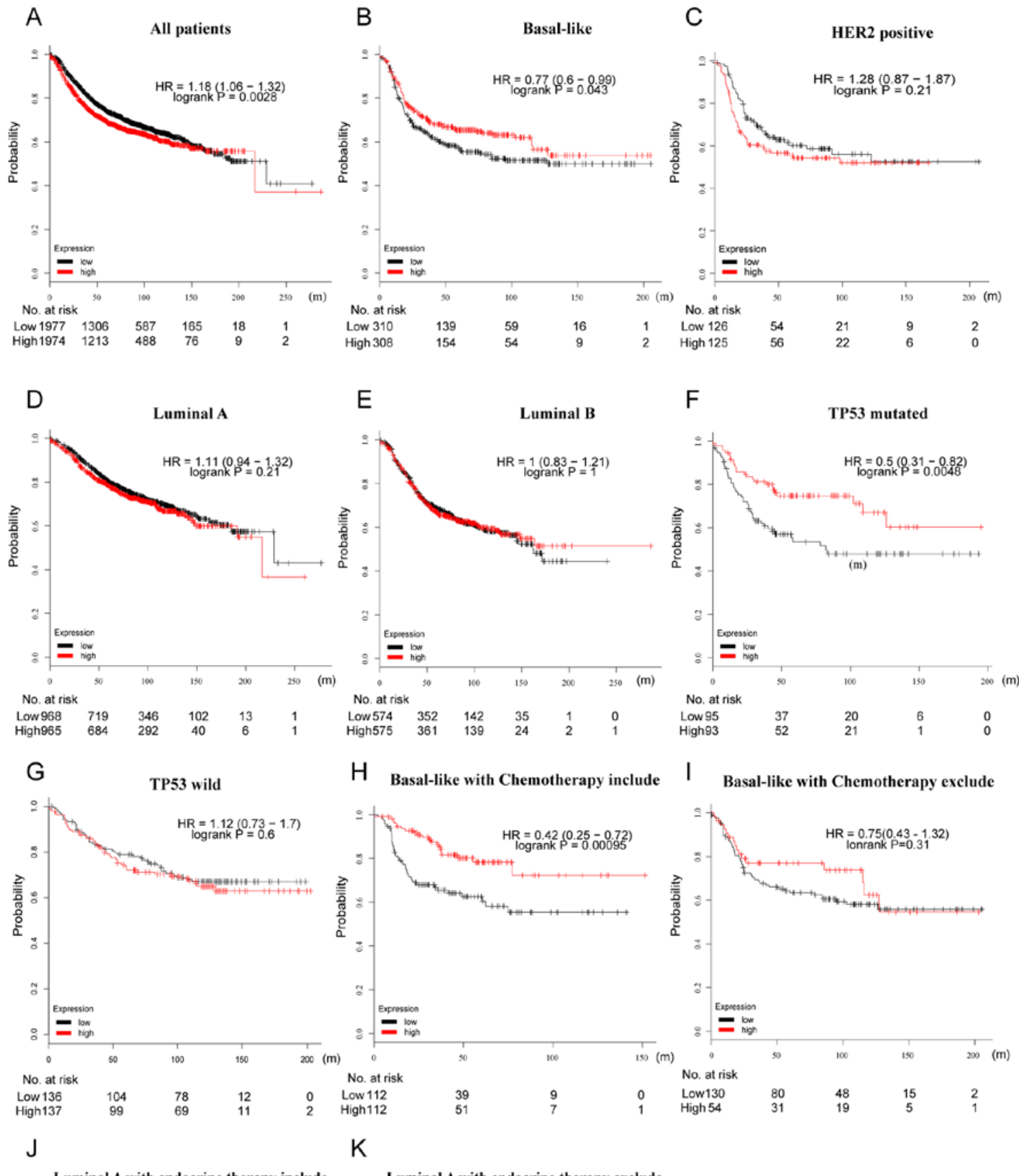

$\mathrm{H}$ Basal-like with Chemotherapy include
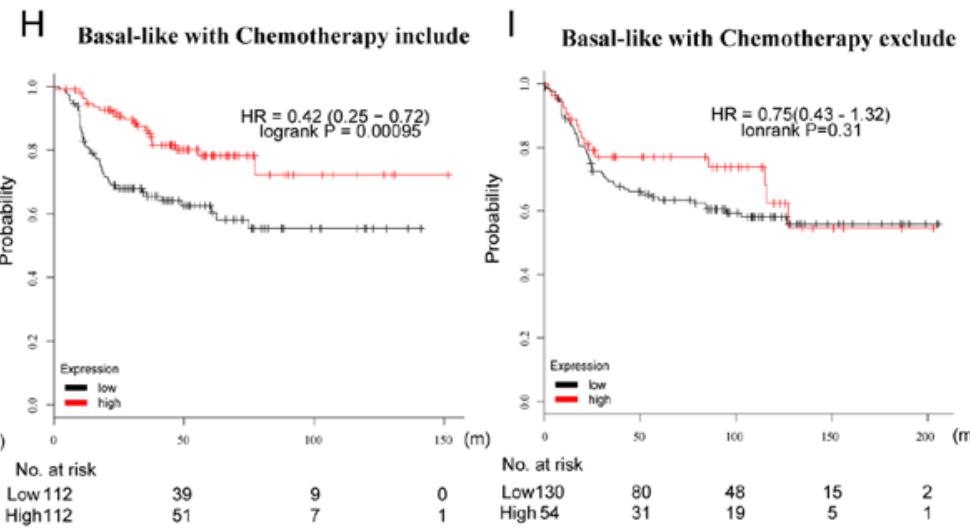

Luminal A with endocrine therapy include

$\mathrm{K}$

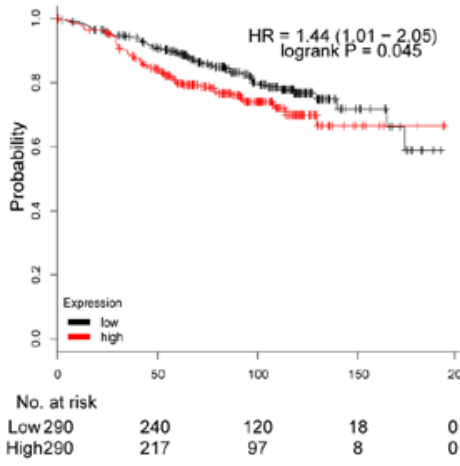

Luminal A with endocrine therapy exclude

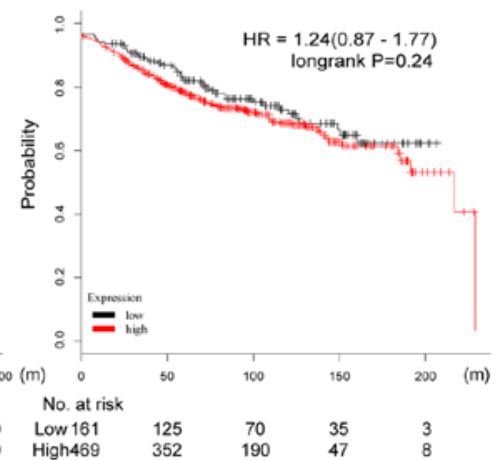

Figure 5. Prognostic value of CXCR4 in terms of RFS in BC. (A) High mRNA expression of CXCR4 was significantly associated with longer RFS in all patients with BC. High mRNA expression of CXCR4 was also associated with longer RFS in patients with (B) basal-like BC, but not in patients with (C) HER2, (D) luminal A or (E) luminal B subtypes of BC. High mRNA expression of CXCR4 was associated with longer RFS in patients with (F) TP53 mutation, but not in patients with (G) wild-type TP53. High mRNA expression of CXCR4 was associated with longer RFS in patients with (H) basal-like BC who had received chemotherapy, while it was not associated with RFS in (I) patients who had not received chemotherapy. High mRNA expression of CXCR4 was associated with shorter RFS in patients with (J) luminal A BC who had received endocrine therapy, and was not associated with RFS in (K) patients who had not received endocrine therapy. CXCR, CXC chemokine receptor; BC, breast cancer; RFS, relapse-free survival; HER2, human epidermal growth factor receptor 2; TP53, cellular tumor antigen p53; HR, hazard ratio. 
A

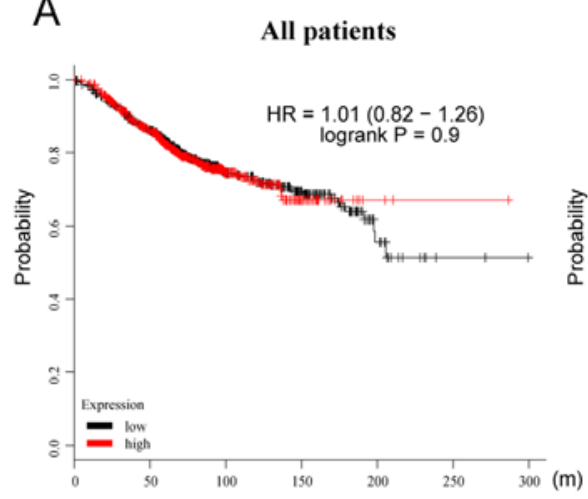

B

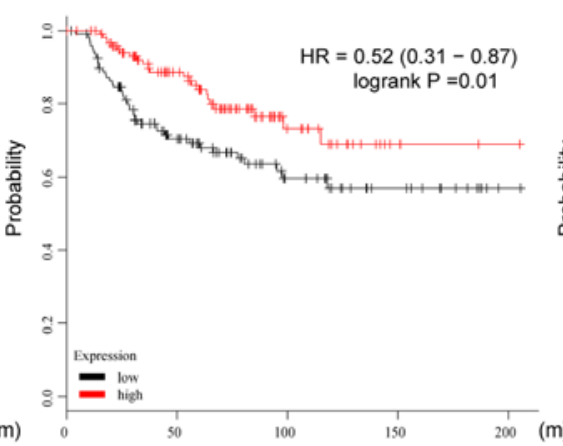

C

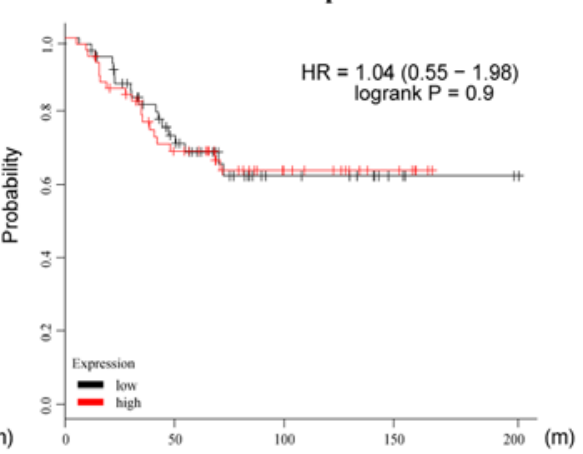

No. at risk

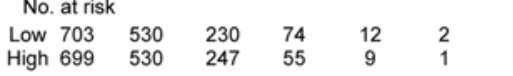

$$
\begin{array}{lllcl}
\text { No. at risk } & & & & \\
\text { Low 120 } & 64 & 28 & 13 & 1 \\
\text { High 121 } & 76 & 22 & 4 & 1
\end{array}
$$

\section{No. at risk}

$\begin{array}{lllll}\text { Low 58 } & 33 & 11 & 4 & 2 \\ \text { High59 } & 34 & 15 & 6 & 0\end{array}$

D

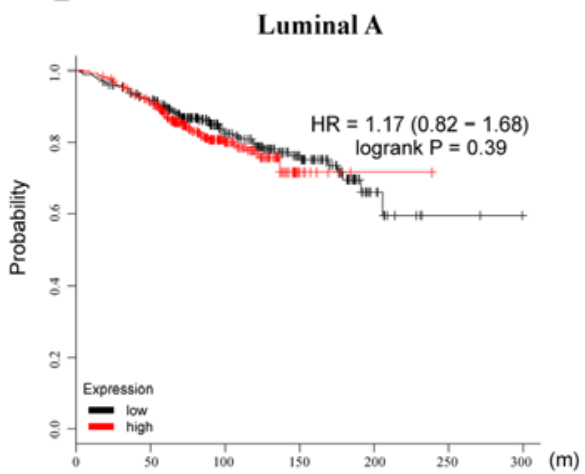

No. at risk

Low $306 \quad 268$

High $305 \quad 265$
E

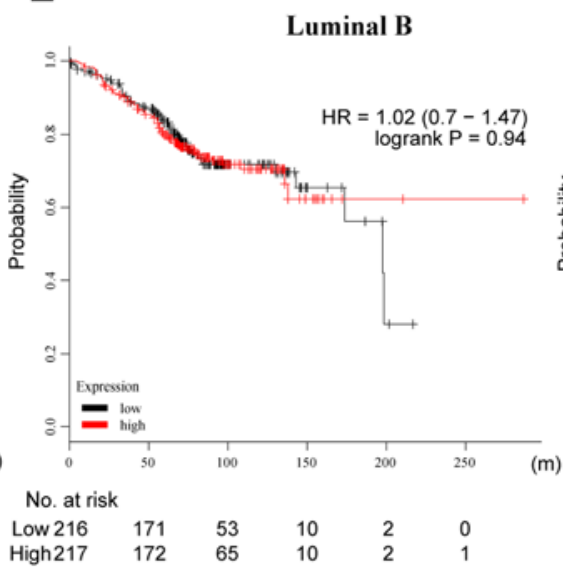

$\mathrm{F}$

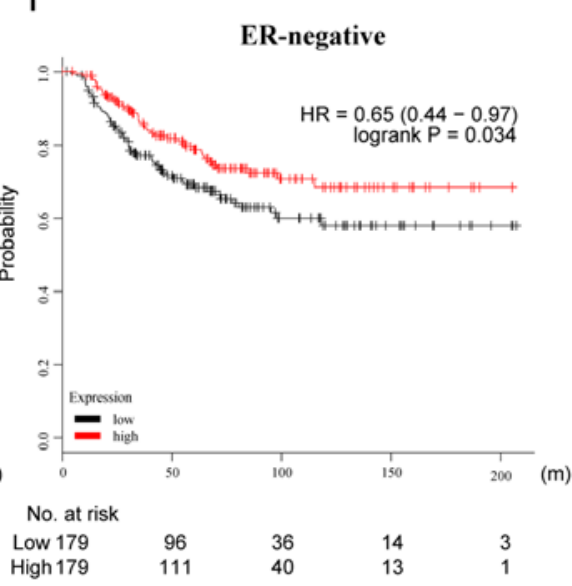

G

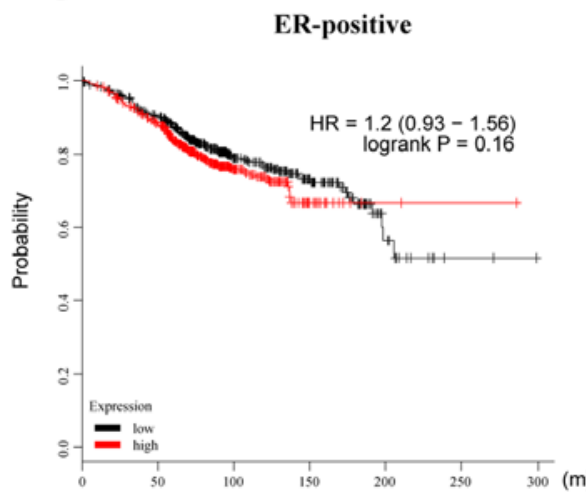

$\mathrm{H}$

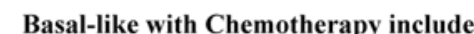

\section{I}
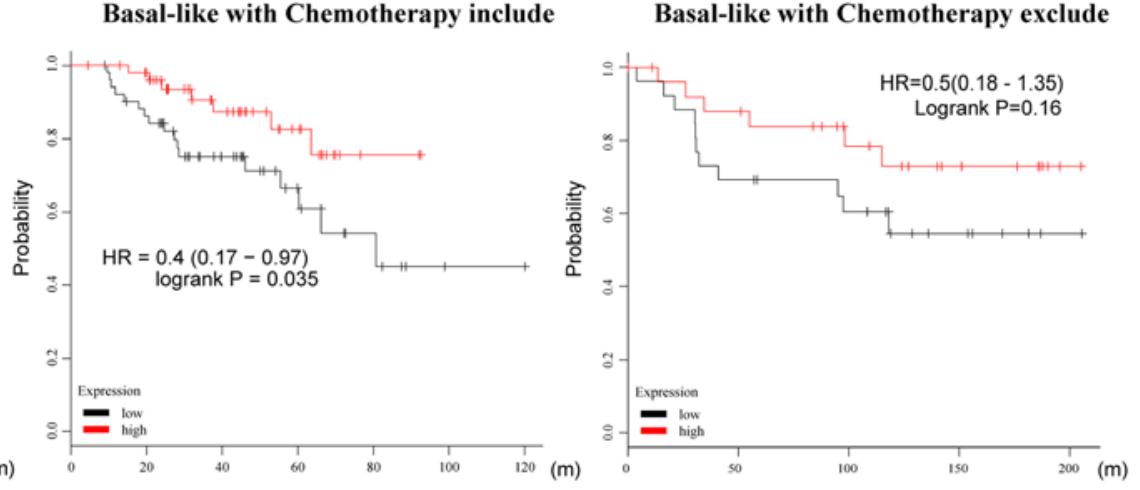

No. at risk No. at risk

No. at risk

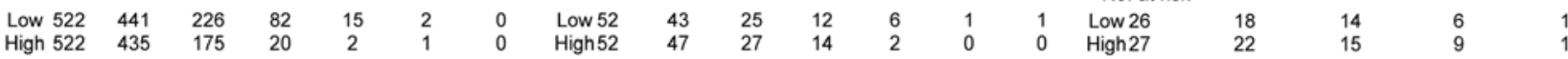

Figure 6. Prognostic value of CXCR4 in terms of OS in BC. (A) No significant correlation was found between high expression of CXCR4 and a longer OS in all patients with BC. High mRNA expression of CXCR4 was associated with longer OS in patients with (B) basal-like BC, but not in patients with the (C) HER2, (D) luminal A or (E) luminal B subtypes of BC. High mRNA expression of CXCR4 was associated with longer OS in patients with (F) ER-negative BC, but not in those with (G) ER-positive BC. High mRNA expression of CXCR4 was associated with longer OS in patients with (H) basal-like BC who had received chemotherapy, while it was not associated with OS in (I) patients who had not received chemotherapy. CXCR, CXC chemokine receptor; BC, breast cancer; HER2, human epidermal growth factor receptor 2; OS, overall survival; ER, estrogen receptor; HR, hazard ratio.

prevents cancer cell proliferation (39). A previous study found that CXCR3 inhibition is effective in both $\mathrm{BC}$ and host compartments (40), while another previous study revealed that CXCR3 deficiency induced cancer development by promoting macrophage M2 polarization in a murine BC model (41). Thus,
CXCR3 has multifaceted roles; it mediates the recruitment of tumor-infiltrating lymphocytes into the cancer microenvironment, resulting in a favorable clinical outcome by inhibiting tumor development and metastasis, and high expression of CXCR3 can promote tumor cell proliferation, migration and 
A

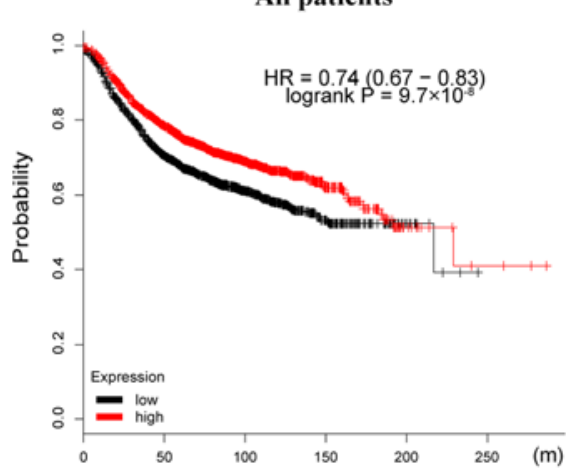

B

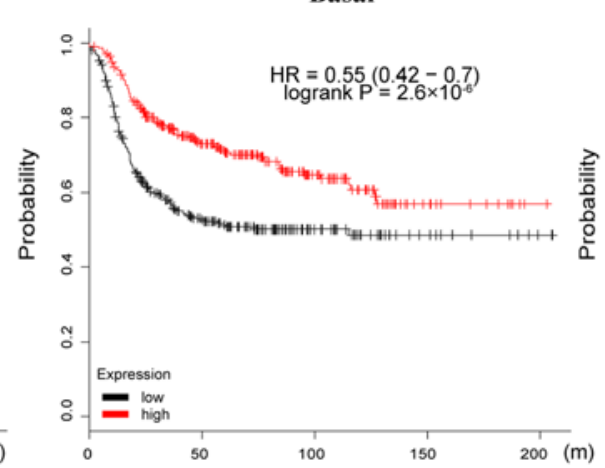

C

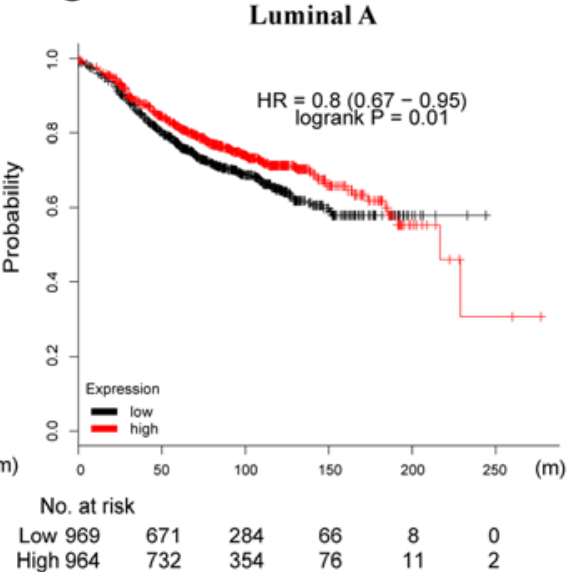

D

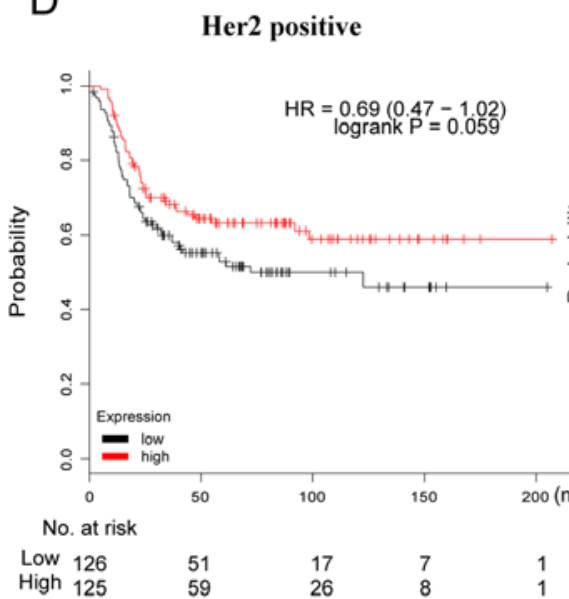

E

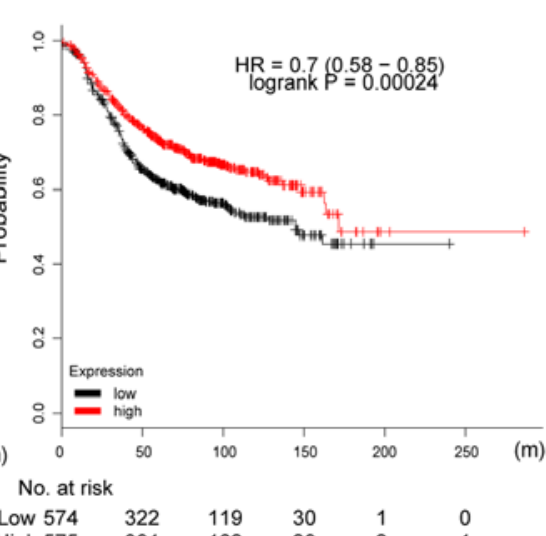

F

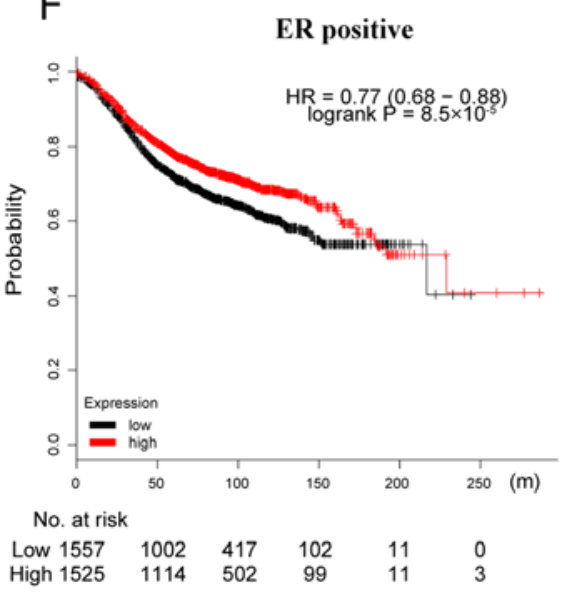

$\mathrm{H}$

ER negative

TP53 mutated

I
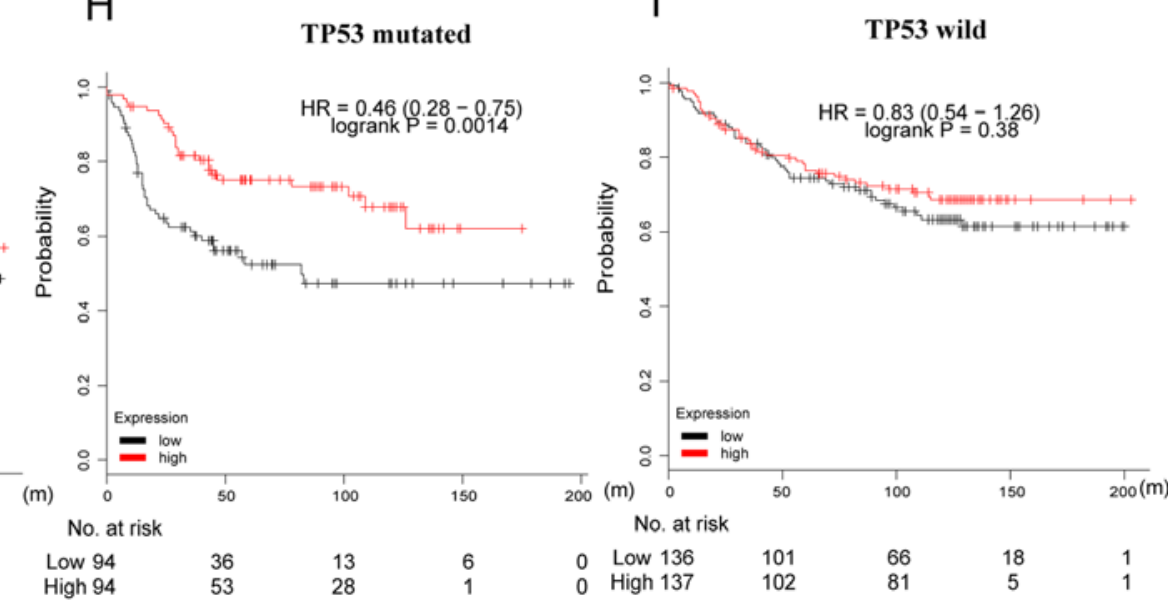

No. at risk

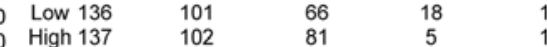

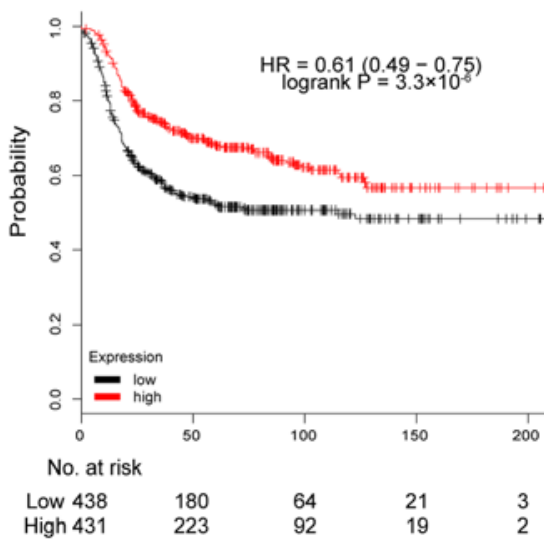

High 94

Figure 7. Prognostic value of CXCR3 in terms of RFS in BC. (A) High mRNA expression of CXCR3 was significantly associated with longer RFS in all patients with BC. High mRNA expression of CXCR3 was associated with longer RFS in patients with the (B) basal-like, (C) luminal A and (D) luminal B subtypes of BC, but not in patients with (E) HER2 BC. High mRNA expression of CXCR3 was associated with longer RFS both in (F) ER-positive and (G) ER-negative patients. High mRNA expression of CXCR3 was associated with longer RFS in patients with (H) TP53 mutated BC, but not in patients with (I) TP53 wild type. CXCR, CXC chemokine receptor; BC, breast cancer; RFS, relapse-free survival; TP53, cellular tumor antigen p53; ER, estrogen receptor; HER2, human epidermal growth factor receptor 2; HR, hazard ratio.

invasion, contributing to poor survival rates for patients (42). In the present study, it was found that CXCR3 is a favorable factor in several subtypes of $\mathrm{BC}$, this is especially the case in basal-like BC.

In conclusion, CXCR4 and CXCR 3 are significantly highly expressed in $\mathrm{BC}$ in comparison with normal samples.
CXCR4 was found to be an adverse prognostic factor in BC; however, for basal-like BC, CXCR4 predicted a better prognosis. CXCR3 was found to be a favorable predictive factor in patients with BC. Furthermore, CXCR4 promoted chemosensitivity in patients with basal-like $\mathrm{BC}$ and induced resistance to endocrine therapy in patients with luminal A BC. 
A

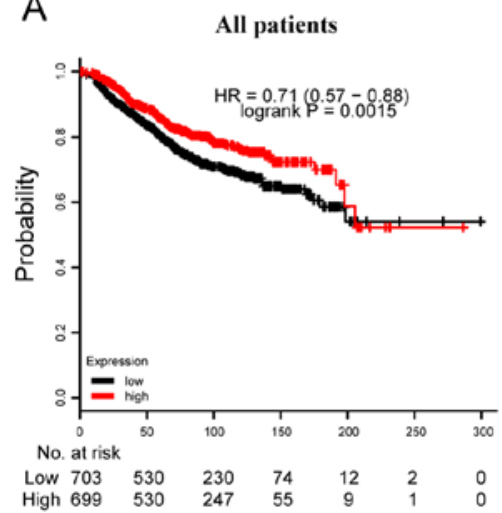

D

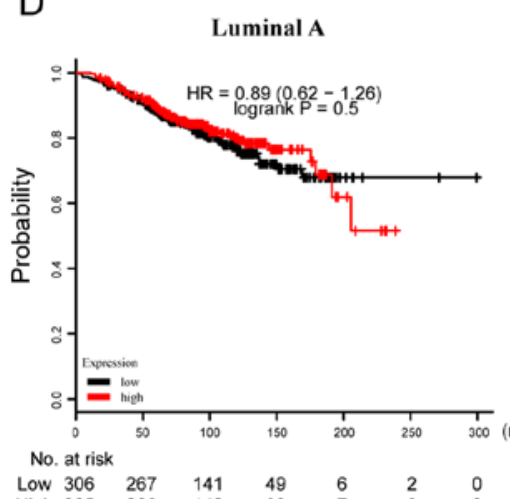

B

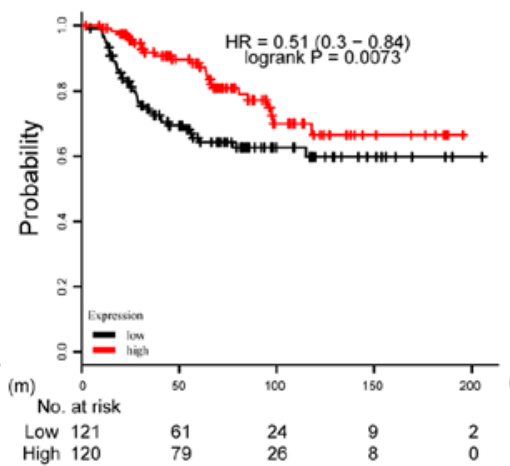

C

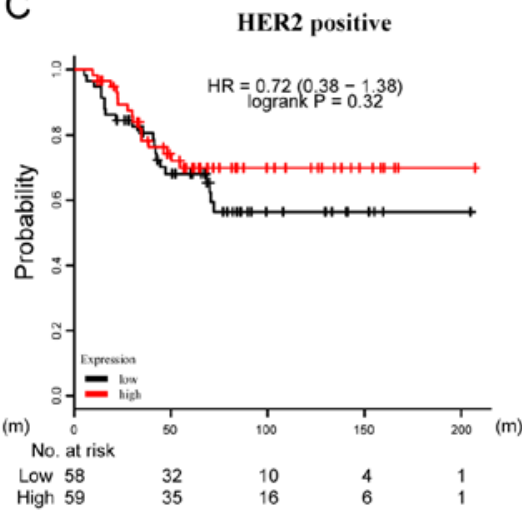

E

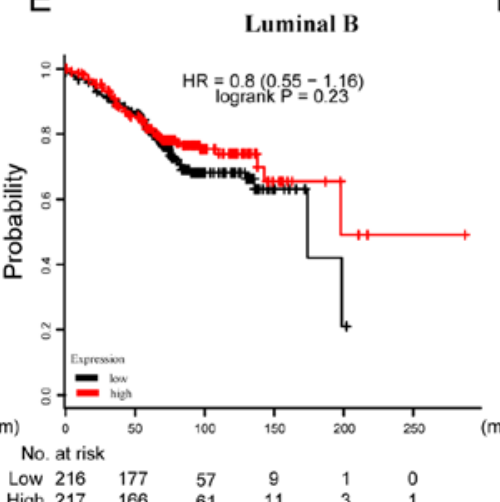

$\mathrm{F}$

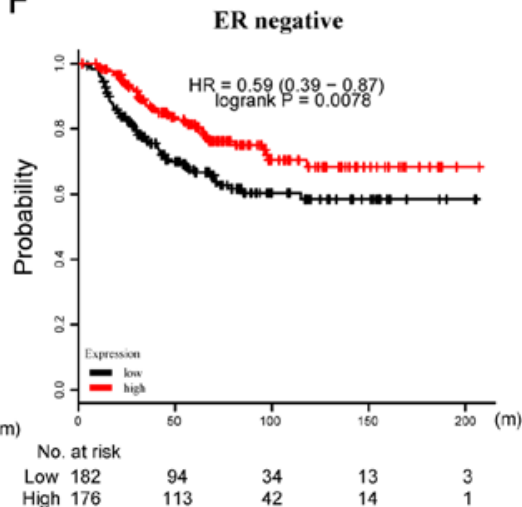

G

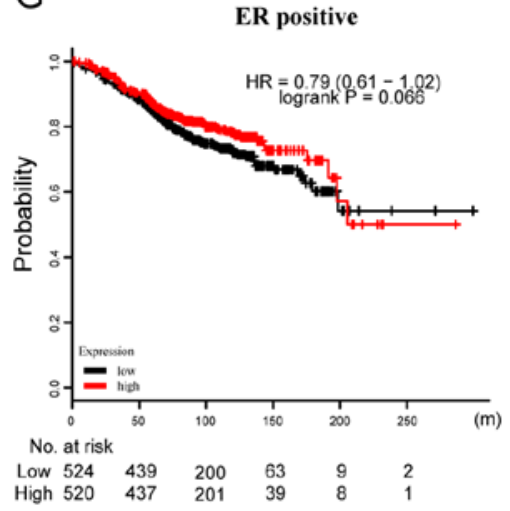

$\mathrm{J}$

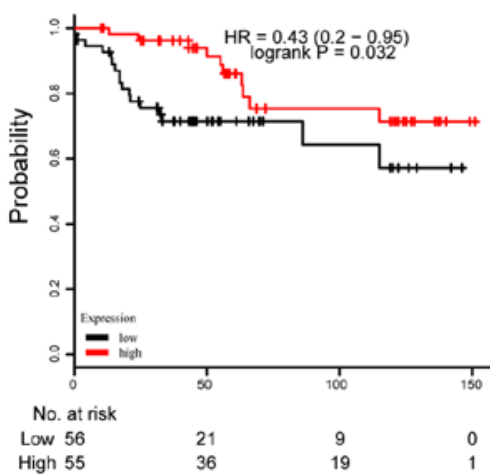

$\mathrm{H}$

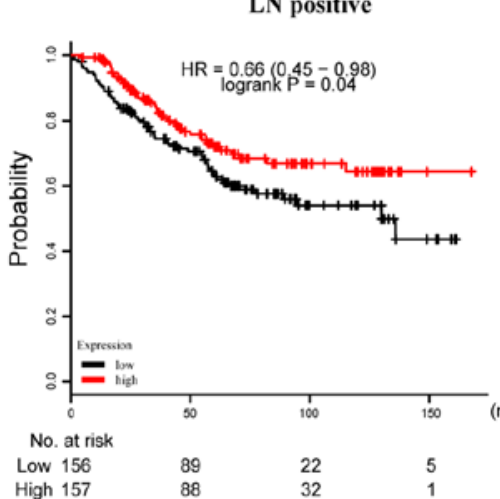

I

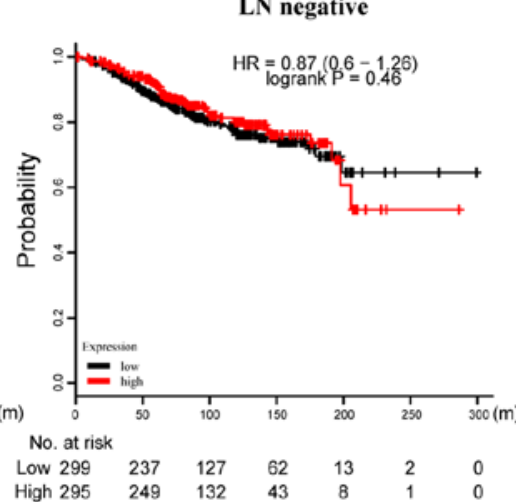

$\mathrm{K}$

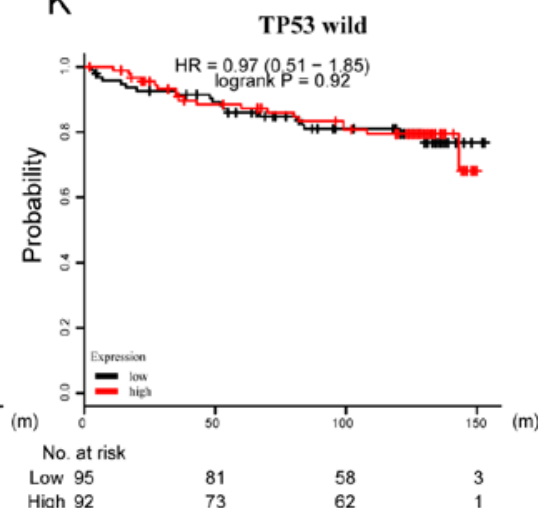

Figure 8. Prognostic value of CXCR3 in terms of OS in BC. (A) High mRNA expression of CXCR3 was significantly associated with longer OS in all patients with BC. High mRNA expression of CXCR3 was associated with longer OS in patients with (B) basal-like BC, but not in patients with (C) HER2, (D) luminal A or (E) luminal B subtypes of BC. High mRNA expression of CXCR3 was associated with longer OS in patients with (F) ER-negative BC, but not in patients with $(\mathrm{G})$ ER-positive BC. High mRNA expression of CXCR3 was associated with longer OS in patients with (H) LN-positive BC, but not patients with (I) LN-negative BC. High mRNA expression of CXCR3 was associated with longer RFS in patients with (J) TP53-mutated BC, but not in patients with (K) TP53 wild-type BC. CXCR, CXC chemokine receptor; BC, breast cancer; OS, overall survival; TP53, cellular tumor antigen p53; ER, estrogen receptor; HER2, human epidermal growth factor receptor 2; LN, lymph node; HR, hazard ratio. 


\section{Acknowledgements}

Not applicable.

\section{Funding}

The present study was supported by the Program for the Cultivation of Youth talents in China Association of Chinese Medicine (SR; grant no. QNRC2-C08; http://www.cacm.org. $\mathrm{cn} /$ ), the Zhejiang Provincial Program for the Cultivation of High-Level Innovative Health Talents (SR; grant no. 2015-43; http://www.zjwjw.gov.cn/) and the Zhejiang Provincial Program for the Cultivation of the Young and Middle-Aged Academic Leaders in Colleges and Universities (SR; grant no. 2017-248; http://www.zjedu.gov.cn/).

\section{Availability of data and materials}

The datasets generated and analyzed during the current study are available in the Oncomine database (http://www.oncomine.org), the GOBO database (http://co.bmc.lu.se/gobo) and the KM plotter tool (http:// kmplot.com/analysis/).

\section{Authors' contributions}

SR, KG and MS contributed to the study design. KZ and FS conducted the data collection. QY and LS performed the statistical analysis. $\mathrm{KG}$ and GF interpreted the data. $\mathrm{KG}$, SR and GF prepared the manuscript. KG and GF performed the literature search. SR and MS were responsible for funds collection.

\section{Ethics approval and consent to participate}

Not applicable.

\section{Patient consent for publication}

Not applicable.

\section{Competing interests}

The authors declare that they have no competing interests.

\section{References}

1. Siegel RL, Miller KD and Jemal A: Cancer statistics, 2018. CA Cancer J Clin 68: 7-30, 2018.

2. Nakasone ES, Hurvitz SA and McCann KE: Harnessing the immune system in the battle against breast cancer. Drugs Context 7: 212520, 2018.

3. Balkwill FR: The chemokine system and cancer. J Pathol 226: 148-157, 2012

4. Zlotnik A, Burkhardt AM and Homey B: Homeostatic chemokine receptors and organ-specific metastasis. Nat Rev Immunol 11: 597-606, 2011

5. Zhu Q, Han X, Peng J, Qin H and Wang Y: The role of CXC chemokines and their receptors in the progression and treatment of tumors. J Mol Histol 43: 699-713, 2012.

6. Vandercappellen J, Van Damme J and Struyf S: The role of CXC chemokines and their receptors in cancer. Cancer Lett 267: 226-244, 2008

7. Holmes WE, Lee J, Kuang WJ, Rice GC and Wood WI: Structure and functional expression of a human interleukin-8 receptor. Science 253: 1278-1280, 1991.
8. Murphy PM and Tiffany HL: Cloning of complementary DNA encoding a functional human interleukin- 8 receptor. Science 253 : 1280-1283, 1991.

9. Kunsch C and Rosen CA: NF-kappa B subunit-specific regulation of the interleukin-8 promoter. Mol Cell Biol 13: 6137-6146, 1993.

10. Ha H, Debnath B and Neamati N: Role of the CXCL8-CXCR1/2 axis in cancer and inflammatory diseases. Theranostics 7: $1543-1588,2017$

11. Tokunaga R, Zhang W, Naseem M, Puccini A, Berger MD, Soni S, McSkane M, Baba H and Lenz HJ: CXCL9, CXCL10, CXCL11/CXCR3 axis for immune activation-A target for novel cancer therapy. Cancer Treat Rev 63: 40-47, 2018.

12. Gupta SK, Lysko PG, Pillarisetti K, Ohlstein E and Stadel JM: Chemokine receptors in human endothelial cells. Functional expression of CXCR4 and its transcriptional regulation by inflammatory cytokines. J Biol Chem 273: 4282-4287, 1998.

13. Coke CJ, Scarlett KA, Chetram MA, Jones KJ, Sandifer BJ, Davis AS, Marcus AI and Hinton CV: Simultaneous activation of induced heterodimerization between CXCR4 chemokine receptor and cannabinoid receptor 2 (CB2) reveals a mechanism for regulation of tumor progression. J Biol Chem 291: 9991-10005, 2016.

14. Forster R, Mattis AE, Kremmer E, Wolf E, Brem G and Lipp M: A putative chemokine receptor, BLR1, directs $B$ cell migration to defined lymphoid organs and specific anatomic compartments of the spleen. Cell 87: 1037-1047, 1996.

15. Mitkin NA, Hook CD, Schwartz AM, Biswas S, Kochetkov DV, Muratova AM, Afanasyeva MA, Kravchenko JE, Bhattacharyya A and Kuprash DV: p53-dependent expression of CXCR5 chemokine receptor in MCF-7 breast cancer cells. Sci Rep 5: 9330, 2015.

16. Szpakowska M, Meyrath M, Reynders N, Counson M, Hanson J, Steyaert $J$ and Chevigné A: Mutational analysis of the extracellular disulphide bridges of the atypical chemokine receptor ACKR3/CXCR7 uncovers multiple binding and activation modes for its chemokine and endogenous non-chemokine agonists. Biochem Pharmacol 153: 299-309, 2018.

17. Ringner M, Fredlund E, Hakkinen J, Borg A and Staaf J: GOBO: Gene expression-based outcome for breast cancer online. PLoS One 6: e17911, 2011.

18. Goldhirsch A, Winer EP, Coates AS, Gelber RD, Piccart-Gebhart M, Thurlimann B and Senn HJ; Panel members: Personalizing the treatment of women with early breast cancer: Highlights of the St Gallen international expert consensus on the primary therapy of early breast cancer 2013. Ann Oncol 24: 2206-2223, 2013.

19. Curtis C, Shah SP, Chin SF, Turashvili G, Rueda OM, Dunning MJ, Speed D, Lynch AG, Samarajiwa S, Yuan Y, et al: The genomic and transcriptomic architecture of 2,000 breast tumours reveals novel subgroups. Nature 486: 346-352, 2012.

20. Finak G, Bertos N, Pepin F, Sadekova S, Souleimanova M, Zhao H, Chen H, Omeroglu G, Meterissian S, Omeroglu A, et al: Stromal gene expression predicts clinical outcome in breast cancer. Nat Med 14: 518-527, 2008.

21. Neve RM, Chin K, Fridlyand J, Yeh J, Baehner FL, Fevr T, Clark L, Bayani N, Coppe JP, Tong F, et al: A collection of breast cancer cell lines for the study of functionally distinct cancer subtypes. Cancer Cell 10: 515-527, 2006.

22. Farmer P, Bonnefoi H, Becette V, Tubiana-Hulin M, Fumoleau P, Larsimont D, Macgrogan G, Bergh J, Cameron D, Goldstein D, et al: Identification of molecular apocrine breast tumours by microarray analysis. Oncogene 24: 4660-4671, 2005.

23. Zhang M, Liu HX, Teng XD, Wang HB, Cui J, Jia SS, Gu XY and Li ZG: The differences in CXCR4 protein expression are significant for the five molecular subtypes of breast cancer. Ultrastruct Pathol 36: 381-386, 2012.

24. Xu TP, Shen H, Liu LX and Shu YQ: The impact of chemokine receptor CXCR4 on breast cancer prognosis: A meta-analysis. Cancer Epidemiol 37: 725-731, 2013.

25. Wang F, Li S, Zhao Y, Yang K, Chen M, Niu H, Yang J, Luo Y, Tang $\mathrm{W}$ and Sheng M: Predictive role of the overexpression for CXCR4, C-Met, and VEGF-C among breast cancer patients: A meta-analysis. Breast 28: 45-53, 2016.

26. Chen HW, Du CW, Wei XL, Khoo US and Zhang GJ: Cytoplasmic CXCR4 high-expression exhibits distinct poor clinicopathological characteristics and predicts poor prognosis in triple-negative breast cancer. Curr Mol Med 13: 410-416, 2013. 
27. Chu QD, Panu L, Holm NT, Li BD, Johnson LW and Zhang S: High chemokine receptor CXCR4 level in triple negative breast cancer specimens predicts poor clinical outcome. J Surg Res 159: 689-695, 2010.

28. Dayer R,Babashah S, Jamshidi S and Sadeghizadeh M: Upregulation of CXC chemokine receptor 4-CXC chemokine ligand 12 axis ininvasive breast carcinoma: A potent biomarker predicting lymph node metastasis. J Cancer Res Ther 14: 345-350, 2018.

29. Lefort S, Thuleau A, Kieffer Y, Sirven P, Bieche I, Marangoni E, Vincent-Salomon A and Mechta-Grigoriou F: CXCR4 inhibitors could benefit to HER2 but not to triple-negative breast cancer patients. Oncogene 36: 1211-1222, 2017.

30. Ierano C, Basseville A, To KK, Zhan Z, Robey RW, Wilkerson J, Bates SE and Scala S: Histone deacetylase inhibitors induce CXCR4 mRNA but antagonize CXCR4 migration. Cancer Biol Ther 14: 175-183, 2013.

31. Duffy MJ, Synnott NC and Crown J: Mutant p53 in breast cancer: Potential as a therapeutic target and biomarker. Breast Cancer Res Treat 170: 213-219, 2018.

32. Rakha EA, Elsheikh SE, Aleskandarany MA, Habashi HO, Green AR, Powe DG, El-Sayed ME, Benhasouna A, Brunet JS, Akslen LA, et al: Triple-negative breast cancer: Distinguishing between basal and nonbasal subtypes. Clin Cancer Res 15 2302-2310, 2009.

33. Chen Y, Jacamo R, Konopleva M, Garzon R, Croce C and Andreeff M: CXCR4 downregulation of let-7a drives chemoresistance in acute myeloid leukemia. J Clin Invest 123: 2395-2407, 2013.

34. Heckmann D, Maier P, Laufs S, Wenz F, Zeller WJ, Fruehauf S and Allgayer H: CXCR4 expression and treatment with SDF-1a or plerixafor modulate proliferation and chemosensitivity of colon cancer cells. Transl Oncol 6: 124-132, 2013.

35. Liang S, Peng X, Li X, Yang P, Xie L, Li Y, Du C and Zhang G: Silencing of CXCR4 sensitizes triple-negative breast cancer cells to cisplatin. Oncotarget 6: 1020-1030, 2015.
36. Yang SX, Loo WT, Chow LW, Yang XH, Zhan Y, Fan LJ, Zhang F, Chen L, Wang QL, Xiao HL, et al: Decreased expression of C-erbB-2 and CXCR4 in breast cancer after primary chemotherapy. J Transl Med 10 (Suppl 1): S3, 2012.

37. Rhodes LV, Short SP, Neel NF, Salvo VA, Zhu Y, Elliott S, Wei Y, Yu D, Sun M, Muir SE, et al: Cytokine receptor CXCR4 mediates estrogen-independent tumorigenesis, metastasis, and resistance to endocrine therapy in human breast cancer. Cancer Res 71: 603-613, 2011.

38. Park S, Lee SK, Paik HJ, Ryu JM, Kim I, Bae SY, Yu J, Kim SW, Lee JE and Nam SJ: Adjuvant endocrine therapy alone in patients with node-positive, luminal A type breast cancer. Medicine 96: e6777, 2017.

39. Ma B, Khazali A and Wells A: CXCR3 in carcinoma progression. Histol Histopathol 30: 781-792, 2015.

40. Zhu G, Yan HH, Pang Y, Jian J, Achyut BR, Liang X, Weiss JM, Wiltrout RH, Hollander MC and Yang L: CXCR3 as a molecular target in breast cancer metastasis: Inhibition of tumor cell migration and promotion of host anti-tumor immunity. Oncotarget 6: 43408-43419, 2015.

41. Oghumu S, Varikuti S, Terrazas C, Kotov D, Nasser MW, Powell CA, Ganju RK and Satoskar AR: CXCR3 deficiency enhances tumor progression by promoting macrophage M2 polarization in a murine breast cancer model. Immunology 143: 109-119, 2014.

42. Bronger H, Karge A, Dreyer T, Zech D, Kraeft S, Avril S, Kiechle $M$ and Schmitt M: Induction of cathepsin B by the CXCR3 chemokines CXCL9 and CXCL10 in human breast cancer cells. Oncol Lett 13: 4224-4230, 2017.

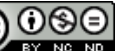

\footnotetext{
This work is licensed under a Creative Common Attribution-NonCommercial-NoDerivatives 4.0 International (CC BY-NC-ND 4.0) License.
} 